\title{
Hypoxia-Induced Intracellular
} and Extracellular Heat Shock Protein gp96 Increases PaclitaxelResistance and Facilitates Immune Evasion in Breast Cancer

OPEN ACCESS

Edited by:

Ri Cui,

Wenzhou Medical University, China

Reviewed by:

Dhrubajyoti Chattopadhyay,

Sister Nivedita University, India

Peng Zou,

Wenzhou Medical University, China

${ }^{*}$ Correspondence:

Hui Pang

panghui@hrbmu.edu.cn

${ }^{t}$ These authors share first authorship

Specialty section:

This article was submitted to Molecular and Cellular Oncology,

a section of the journal

Frontiers in Oncology

Received: 28 September 2021 Accepted: 02 November 2021 Published: 20 December 2021

Citation:

Tian T, Han J, Huang J, Li S and Pang $H$ (2021) Hypoxia-Induced Intracellular and Extracellular Heat

Shock Protein gp96 Increases Paclitaxel-Resistance and Facilitates Immune Evasion in Breast Cancer.

Front. Oncol. 11:784777.

doi: 10.3389/fonc.2021.784777

\author{
Tian Tian ${ }^{1+}$, Jiguang $\mathrm{Han}^{2 \dagger}$, Jian Huang ${ }^{1}$, Shangziyan $\mathrm{Li}^{1}$ and Hui Pang ${ }^{1 *}$ \\ 1 Department of Oncology, Harbin Medical University Cancer Hospital, Harbin, China, ${ }^{2}$ Department of Surgical Oncology, \\ Harbin Medical University Cancer Hospital, Harbin, China
}

Backgrounds: Hypoxia contributes to cancer progression, drug resistance and immune evasion in various cancers, including breast cancer (BC), but the molecular mechanisms have not been fully studied. Thus, the present study aimed to investigate this issue.

Methods: The paclitaxel-sensitive BC (PS-BC) cells were administered with continuous low-dose paclitaxel treatment to establish paclitaxel-resistant BC (PR-BC) cells. Exosomes were isolated/purified by using the commercial kit, which were observed by Transmission electron microscopy (TEM). Cell viability was measured by MTT assay, cell apoptosis was determined by flow cytometer (FCM). Gene expressions were respectively measured by Real-Time qPCR, Western Blot and immunofluorescence staining assay. The peripheral mononuclear cells (PBMCs) derived $\mathrm{CD}^{+} \mathrm{T}$ cells were obtained and cocultured with gp96-containing exosomes, and cell proliferation was evaluated by EdU assay. ELISA was employed to measure cytokine secretion in $C D 8^{+} T$ cells' supernatants.

Results: HSP gp96 was significantly upregulated in the cancer tissues and plasma exosomes collected from BC patients with paclitaxel-resistant properties. Also, continuous low-dose paclitaxel treatment increased gp96 levels in the descendent PR$\mathrm{BC}$ cells and their exosomes, in contrast with the parental PS-BC cells. Upregulation of gp96 increased paclitaxel-resistance in PS-BC cells via degrading p53, while gp96 silence sensitized PR-BC cells to paclitaxel treatments. Moreover, PR-BC derived gp96 exosomes promoted paclitaxel-resistance in PS-BC cells and induced pyroptotic cell death in the $\mathrm{CD}^{+} \mathrm{T}$ cells isolated from human peripheral blood mononuclear cells (pPBMCs). Furthermore, we noticed that hypoxia promoted gp96 generation and secretion through upregulating hypoxia-inducible factor 1 (HIF-1), and hypoxia increased paclitaxel-resistance and accelerated epithelial-mesenchymal transition (EMT) in PS-BC cells. 
Conclusions: Hypoxia induced upregulation of intracellular and extracellular gp96, which further degraded p53 to increase paclitaxel-sensitivity in BC cells and activated cell pyroptosis in $\mathrm{CD}^{+} \mathrm{T}$ cells to impair immune surveillance.

Keywords: heat shock protein gp96, p53, breast cancer, cancer immunology, paclitaxel-resistance

\section{BACKGROUNDS}

Paclitaxel-resistance is a huge obstacle for the treatment of breast cancer (BC), which makes this chemical drug ineffective for the treatment of $\mathrm{BC}$, resulting in worse prognosis and recurrence in $B C$ patients $(1,2)$. Although researchers have used paclitaxel-other chemical drugs combined therapy to treat $\mathrm{BC}$, the therapeutic efficacy of this treatment strategies is still seriously limited as the results of its unclear molecular mechanisms (3-5). Thus, it becomes necessary and meaningful to delve into the molecular mechanisms by which $\mathrm{BC}$ cells transform from paclitaxel-sensitive BC (PS-BC) cells into the paclitaxel-resistant BC (PR-BC) cells. In recent studies, it draws our attention that cancer cells derived exosomes play critical role in regulating paclitaxel-resistance in $\mathrm{BC}$ $(6,7)$. Specifically, data from Pederson et al. show that paclitaxel treatment is able to alter the secretion patterns of extracellular vesicles in BC cells (6), and Yang et al. further evidence that chemotherapy-elicited microRNAs (miRNAs)-containing exosomes promote BC cell stemness and chemoresistance (7). Heat shock protein (HSP) glucoprotein 96 (gp96) is reported as the components of cancer derived exosomes $(8,9)$, and gp96 itself is related with the aggressiveness of $\mathrm{BC}(10,11)$ and paclitaxelresistance in ovarian cancer cells (12). However, it is still not reported whether gp96-containing exosomes involve in regulating paclitaxel-resistance in BC.

Hypoxia is a typical feature in solid tumors when tumor volume reaches about $2 \mathrm{~mm}^{3}$, and the inner cancer cells suffer from oxygen and nutrients deprivation (13-15). Under those environmental stresses, the expression patterns of various cancer-associated genes are altered, and a subgroup of the cancer cells acquire the tumorpromoting properties to facilitate angiogenesis and cancer metastasis (16-18). Interestingly, recent studies also evidence that hypoxia influences chemo-resistance in multiple cancers, such as glioma (19), hepatocellular carcinoma (20), and BC (21). Of note, Tang et al. report that hypoxia promotes $\mathrm{BC}$ cell growth via modulating glycogen metabolic program (22), and data from $\mathrm{Wu}$ et al. suggest that hypoxia facilitates metastasis and chemoresistance in BC (21). To our knowledge, hypoxia is capable of inducing the upregulation of HSPs to initiate the protective mechanisms in the cells under hypoxic stresses (23-25), and Kutomi et al. evidence that hypoxia upregulates gp96 levels (26). In addition, hypoxia-inducible factor 1 (HIF-1) is the key hypoxia-associated gene, which is reported to regulate BC progression (27-29) and paclitaxelresistance $(21,30)$. Interestingly, as previously reported, production of gp96 is coordinately induced by heat shock factor 1 (HSF-1) and HIF-1 (9), and both HIF-1 and gp96 are elevated in malignant mesothelioma (31).

To our knowledge, human immune system initially eliminates cancer cells through recognizing tumor associated antigens, which is known as immune surveillance (32-34), and the main tumor killer cells are considered as CD8 ${ }^{+}$T lymphocytes $(35,36)$. However, cancer cells develop strategies to hide tumor antigens or induce immune cell death to impair the anti-tumor functions of the immune system, and this process is known as immune evasion $(35,36)$. According to the previous literatures (37-39), cancer cells derived exosomes are pivotal to induce immune cell death, and Hong et al. report that non-small cell lung cancer (NSCLC) derived PD-L1 containing exosomes promote $\mathrm{CD}^{+} \mathrm{T}$ cell death (35). Interestingly, gp96 is reported to be closely associated with immune cells infiltration in BC $(9,40)$. Researchers notice that gp96 affects $\mathrm{CD} 4^{+}$and $\mathrm{CD} 8^{+} \mathrm{T}$-lymphocytes in various types of invasive breast carcinoma (40), and extracellular gp96 has been considered as biomarkers for immune surveillance and immune evasion (9). Moreover, recent data suggest that there exist links between hypoxia and immune evasion (41), and hypoxiainduced extracellular HSPs influences immune surveillance and immune evasion (9).

Based on all the existed information, the present study was designed to mainly investigate the three academic issues as follows: (1) The role of gp96 in regulating paclitaxel-resistance in $\mathrm{BC}$, and uncover the potential mechanisms. (2) The mechanisms by which gp96-containing exosomes facilitate immune evasion in BC. (3) The involvement of hypoxia in regulating paclitaxel-resistance and EMT in BC.

\section{MATERIALS AND METHODS}

\section{Clinical Specimen Collection}

$\mathrm{BC}$ patients $(\mathrm{N}=67)$ were recruited in the Harbin Medical University Cancer Hospital from 2016 to 2020, and the cancerous and non-cancerous tissues were collected by surgery, were judged by two experienced pathologists in our hospital, and were immediately stored at $-80^{\circ} \mathrm{C}$ conditions for further utilization. According to their therapy treatment history, the $\mathrm{BC}$ patients were divided into two groups with $(\mathrm{N}=34$, considered as $\mathrm{PR}-\mathrm{BC}$ patients $)$ or without $(\mathrm{N}=$ 33, considered as PS-BC patients) paclitaxel treatment history. Specifically, the patients who had paclitaxel treatment history were considered as PR-BC patients, whereas the patients did not receive any chemotherapy were deemed as PS-BC patients. The clinical characteristics of the involved patients were listed in Table $\mathbf{1}$. The clinical experiments were approved by the Ethics Committee Affiliated to Harbin Medical University Cancer Hospital, and the informed consent forms were also signed by all the participates.

\section{Cell Culture, Treatment and Vectors Transfection}

The human TNBC cell lines (MDA-MB-453 and MCF7) were purchased from BeNa Culture Collection (Beijing, China), All 
TABLE 1 | Correlations of gp96 mRNA with the clinical parameters in BC patients

\begin{tabular}{|c|c|c|c|c|}
\hline & \multirow[t]{2}{*}{ Cases (N) } & \multicolumn{2}{|c|}{ mRNA levels of gp96 } & \multirow[t]{2}{*}{$P$ values } \\
\hline & & Low & High & \\
\hline \multicolumn{4}{|l|}{ Age (Years) } & 0.432 \\
\hline$\leq 40$ & 23 & 11 & 12 & \\
\hline$>40$ & 44 & 31 & 13 & \\
\hline \multicolumn{4}{|c|}{ Clinical stage } & 0.012 \\
\hline |/II & 41 & 21 & 20 & \\
\hline III/IV & 26 & 12 & 14 & \\
\hline \multicolumn{4}{|c|}{ Lymph node metastasis } & 0.001 \\
\hline Negative & 18 & 10 & 8 & \\
\hline Positive & 49 & 23 & 26 & \\
\hline \multicolumn{4}{|c|}{ Tumor size (cm) } & $<0.0001$ \\
\hline$\leq 4$ & 29 & 19 & 10 & \\
\hline$>4$ & 38 & 15 & 23 & \\
\hline
\end{tabular}

The bold values means that the data was statistical significance.

cells were regularly authenticated using short tandem repeat (STR) DNA profiling and tested to confirm that they were mycoplasma contamination-free. The above cells were maintained in the DMEM medium (Gibco, USA) containing $10 \%$ fetal bovine serum (FBS, Gibco) under the conditions with $5 \% \mathrm{CO}_{2}$ atmosphere at $37^{\circ} \mathrm{C}$. In addition, according to the experimental protocols recorded in our previous work (42), the paclitaxel-resistant MDA-MB-453/PTX and MCF7/PTX cell lines was established by treating the parental paclitaxelsensitive $\mathrm{BC}$ cells with continuous paclitaxel treatment in a step-wise manner. The PR-BC cells were maintained in the DMEM medium (Gibco, USA) containing 10\% fetal bovine serum, and the PR-BC cells at passage 2 to 4 with paclitaxelresistant properties were used in this study. Moreover, the vectors for gp96 overexpression/downregulation and p53 overexpression were synthesized by Sangon Biotech (Shanghai, China), which were delivered into the TNBC cells by using the Lipofectamine 2000 transfection reagent (Invitrogen, USA). Moreover, the PS-BC cells were exposed to the hypoxic environment $\left(0.2 \%\right.$ oxygen, $5 \% \mathrm{CO}_{2}$, and $\left.37^{\circ} \mathrm{C}\right)$ for three days to establish the hypoxic PS-BC cell models as previously described (43).

\section{Isolation and Purification of the Exosomes}

The EXO Quick-Exosome Isolation kit (Biosciences System, USA) was purchased to obtain the exosomes from patients' plasma and cells' supernatants in keeping with the manufacturer's protocols. Specifically, for the plasma exosomes, the patient blood was collected and were subjected to centrifugation $(3000 \mathrm{~g}, 15 \mathrm{~min})$ to acquire the supernatants, which were regarded as plasma. Then, $300 \mu \mathrm{l}$ of the plasma were mixed with the exosome precipitation solution of the kit, and the plasma exosomes were further collected. For the cell-derived exosomes, the BC cells were cultured in vitro and their supernatants were collected through sequential centrifugation, including $300 \mathrm{~g}$ for $10 \mathrm{~min}, 2000 \mathrm{~g}$ for $15 \mathrm{~min}, 12,000 \mathrm{~g}$ for $30 \mathrm{~min}$ to remove the cells and debris, which were further filtered by $0.22 \mu \mathrm{m}$ filters (Millipore, USA). The filtered supernatants were mixed with the working solution of the kit, and the exosomes were isolated and purified according to the kit's instructions.

\section{Transmission Electron Microscopy (TEM)}

To observe the morphologies of the exosomes, we performed the TEM assay based on the previous protocols. The purified exosomes were fixed with $1 \%$ glutaraldehyde for $10 \mathrm{~min}$ at room temperature, and the exosomes were further placed onto a formvar carbon-coated 300-mesh copper electron microscopy grids (Agar Scientific Ltd., USA) for $5 \mathrm{~min}$, and the exosomes were stained with $2 \%$ uranyl oxalate for $2 \mathrm{~min}$. The grids were washed with PBS and a TEM machine (Jeol, Japan) was employed to observe and photograph the exosomes.

\section{Preparation of the $\mathrm{CD8}^{+} \mathrm{T}$ Cells}

The $\mathrm{CD}^{+} \mathrm{T}$ cells were isolated and cultured according to the previous literature (35). Briefly, the volunteers were recruited and the blood was obtained, which were further subjected to the Ficoll kit (Sigma-Aldrich, USA) to obtain the peripheral mononuclear cells (PBMCs) in keeping with the reagent's protocols. A flow cytometer (BD Bioscience, USA) was further used to acquire the $\mathrm{CD}^{+} \mathrm{T}$ subgroup from the PBMCs as previously described (44).

\section{Real-Time qPCR}

Total RNA was extracted from BC tissues and cells through using the TRIzol reagent (Beyotime, Shanghai, China), and further Real-Time qPCR was performed to quantify genes expressions. Specifically, the cDNA synthesis kit (ThermoFisher Scientific, CA, USA) was used to reversely transcribed the mRNA into complementary DNA (cDNA), through using the Bio-Rad RealTime qPCR detection system (Bio-Rad, CA, USA), we performed Real-Time qPCR to determine the mRNA levels of HSP gp96, p53, IL-1 $\beta$, IL-18, ZEB1, Vimentin, Twist, Slug and Snail, and the relevant expression levels of the above genes were normalized by the GAPDH. The primers were designed and constructed by Sangon Biotech (Shanghai, China), and their detailed sequences were shown in Table 2 .

\section{Western Blot Analysis}

RIPA lysis buffer (Biotime, Hangzhou, China) was used to obtain total proteins from $\mathrm{BC}$ tissues and cells, and the quality of the protein was determined by BCA kit (Pierce, USA). Proteins were separated by $10 \%$ SDS-PAGE, and were subsequentially transferred onto the PVDF membranes (Millipore, MA, USA). The membranes were blocked by $5 \%$ non-fat milk, and incubated with the primary antibodies against gp96 (1:1000, \#ab227293, Abcam, UK), TSG101 (1:1000, \#ab125011, Abcam, UK), p53 (1:2000, \#ab1101, Abcam, UK), GAPDH (1:2000, \#ab8245, Abcam, UK), CD63 (1:1500, \#ab271286, Abcam, UK) and $\beta$-actin (1:2000, \#ab179467, Abcam, UK) at $4^{\circ} \mathrm{C}$ overnight. In the second day, the membranes were probed with the secondary antibodies for $1 \mathrm{~h}$ at room temperature, and an ECL system (Bio-Rad, CA, USA) was employed to visualize the protein bands. The expression levels of the proteins were normalized by GAPDH.

\section{MTT Assay}

MTT assay was performed to evaluate cell viability as previously reported. In brief, the BC cells were cultured in the 96-well plates in 
TABLE 2 | The primer sequences for Real-Time qPCR.

\begin{tabular}{|c|c|}
\hline Gene name & Primer sequences \\
\hline HSP gp96 & $\begin{array}{l}\text { Forward: 5'-GCT TCG GTC AGG GTA TCT TाT-3' } \\
\text { Reverse: 5'-CAC CTT TGC ATC AGG GTC AAT-3' }\end{array}$ \\
\hline GAPDH & $\begin{array}{l}\text { Forward 5'-TGT TGC CAT CAA TGA CCC CTT-3' } \\
\text { Reverse 5'-CTC CAC GAC GTA CTC AGC G-3' }\end{array}$ \\
\hline p53 & $\begin{array}{l}\text { Forward: 5'-GAC GGT GAC ACG CTT CCC TG-3' } \\
\text { Reverse: 5'-CAC CAC CAC ACT ATG TCG-3' }\end{array}$ \\
\hline IL-1 $1 \beta$ & $\begin{array}{l}\text { Forward: 5'-GGC AGG TGG TAT CGA TCA TC-3' } \\
\text { Reverse: 5'-CAC CTT GGA TाT GAC TTC TA-3' }\end{array}$ \\
\hline IL-18 & $\begin{array}{l}\text { Forward: 5'-GCT GGC TGT AAC CCT CTC TG-3' } \\
\text { Reverse: 5'-TTC CTC CTT TTG GCA AGC TA-3' }\end{array}$ \\
\hline ZEB1 & $\begin{array}{l}\text { Forward: 5'-GCT GGC AAG ACA ACG TGA AAG-3' } \\
\text { Reverse: 5'-GCC TCA GGA TAA ATG ACG GC-3' }\end{array}$ \\
\hline Vimentin & $\begin{array}{l}\text { Forward: 5'-CGT CCA CAC GCA CCT ACA G-3' } \\
\text { Reverse: 5'-GGG GGA TGA GGA ATA GAG GCT-3' }\end{array}$ \\
\hline Twist & $\begin{array}{l}\text { Forward: 5'-GGA CAA GCT GAG CAA GAT TCA-3' } \\
\text { Reverse: 5'-CGG AGA AGG CGT AGC TGA G-3' }\end{array}$ \\
\hline Slug & $\begin{array}{l}\text { Forward: 5'-TGG TCA AGA AAC ATT TCA ACG CC-3', } \\
\text { Reverse: 5'-GGT GAG GAT CTC TGG TाT TGG TA-3' }\end{array}$ \\
\hline Snail & $\begin{array}{l}\text { Forward: 5'-CAC ACG CTG CCT TGT GTC T-3' } \\
\text { Reverse: 5'-GGT CAG CAA AAG CAC GGT T-3' }\end{array}$ \\
\hline Fibronectin & $\begin{array}{l}\text { Forward: 5'-ATG TGG ACC CCT CCT GAT AGT-3' } \\
\text { Reverse: 5'-GCC CAG TGA TाT CAG CAA AGG-3' }\end{array}$ \\
\hline
\end{tabular}

the standard culture conditions, which were further added with MTT reaction solution at the density of $20 \mu \mathrm{l}$ per well for $4 \mathrm{~h}$. Then, the supernatants were carefully discarded, and the formazan was diluted by adding $150 \mu \mathrm{l}$ DMSO. The plates were fully vortexed, and a microplate reader (Molecular Devices, CA, USA) was employed to determine cell viability at the wavelength of $450 \mathrm{~nm}$.

\section{Enzyme Linked Immunosorbent Assay (ELISA)}

The cytokine secretion (IL-1 $\beta$ and IL-18) in BC cells' supernatants were determined by performing ELISA through using their corresponding ELISA kit purchased from RAPIDBIO (CA, USA). The cell supernatants were collected and incubated with the reaction solution, and a microplate reader (Molecular Devices, CA, USA) was further employed to measure the optical density (OD) values at the wavelength of $450 \mathrm{~nm}$, and the relative expression levels of the two cytokines were calculated according to the OD values.

\section{Measurement of Cell Apoptosis by Flow Cytometry (FCM)}

The BC cells with differential treatments and vector transfection were sequentially stained with Annexin V-FITC and PI in the commercial apoptosis detection kit (Solarbio, Beijing, China), and a FCM (BD Bioscience, USA) was employed to examine the apoptotic cell ratio, which were defined as Annexin V-FITC or PI-positive cells. The experiments were conducted in accordance with the manufacturer's instruction.

\section{EdU Assay}

The EdU kit (Solarbio, Beijing, China) was purchased to examine cell proliferation in keeping with the manufacturer's protocol. Specifically, the $\mathrm{CD}^{+} \mathrm{T}$ cells with or without gp96-containing exosomes co-incubation were incubated with EdU reaction solution for $2 \mathrm{~h}$, and the cells were further washed by PBS buffer for three times, fixed by $4 \%$ paraformaldehyde, neutralized by glycine, and reacted with fluorescence dyes. Then, the cells were stained with DAPI to visualize their nucleus, and a fluorescence microscope (Olympus, Japan) was employed to observe and photograph the EdU-positive cells, which were regarded as $\mathrm{CD}^{+} \mathrm{T}$ cells with good proliferative abilities.

\section{Immunofluorescence Staining Assay}

The BC cells were cultured in the $25 \mathrm{~cm}^{3}$ flasks and were fixed by incubating cells with $4 \%$ paraformaldehyde for $20 \mathrm{~min}$ at $37^{\circ} \mathrm{C}$. Then, the fixed cells were washed by PBS buffer for three times to fully remove the residual paraformaldehyde, and were permeabilized by using the PBST buffer (PBS buffer with $0.05 \%$ Triton X-100 supplementation). Then, the cells were sequentially incubated with the primary antibodies (Gasdermin D, 1:200) and secondary antibodies, and the expression levels and cellular localization of the proteins were examined by performing a confocal microscope (Zeiss, Germany).

\section{Animal Experiments}

The MCF7 cells were subcutaneously injected into the dorsal flank of the six-week-old female C57BL/6J mice, and the cell concentration for injection was $1 \times 10^{6}$ cells per mouse, and tumor volume was monitored every 3 days. Until the tumor volume reached about $100 \mathrm{~mm}^{3}$, the gp96-containing or deficient exosomes were injected into the mice tumors, and the tumor volume were further monitored for 6 days with 2 days intervals. The mice were divided into three groups with 6 mice each group, including negative control (NC), gp-96 containing exosomes, and gp-96-deficient exosomes. Then, the mice were anesthetized and sacrificed, and the tumors were obtained and weighed. Our animal experiments were conducted in accordance with the guidelines of the Ethics Committee affiliated to Harbin Medical University Cancer Hospital.

\section{Analysis of the Data}

SPSS 18.0 software was employed to analyze the data in the present study, which had been shown as Means \pm Standard Deviation (SD), and the graphs were generated by using the GraphPad Prism 8.0 software. One-way ANOVA analyzed the differences among multiple groups $(>2)$, while the differences in two groups were compared by performing the student's t-test. Individual experiment was repeated at least 3 times. ${ }^{\star} P<0.05,{ }^{* *} P<0.01$ and ${ }^{\star * *} P<0.001$ were considered as statistical significance.

\section{RESULTS}

\section{Intracellular and Extracellular gp96 Was Closely Related With Cancer Malignancy and Paclitaxel-Resistance in BC}

For the clinical experiments, the cancerous and adjacent noncancerous tissues were collected from BC patients $(\mathrm{N}=67)$, and 
Real-Time qPCR results showed that the mRNA levels of gp96 were significantly increased in $\mathrm{BC}$ tissues comparing to the corresponding normal tissues (Fold changes: 2.12, Figure 1A). Also, the correlation of gp96 expressions with patients' clinical features were analyzed, and our findings suggested that BC patients with higher clinical stage (III-IV), positive lymph node metastasis and higher tumor size $(\geq 5 \mathrm{~cm})$ showed significant high-expressed gp96, but its expression status had nothing to do with patients' age (Table 1). Interestingly, the BC patients were divided into two groups with $(\mathrm{N}=34$, considered as PRBC patients) or without ( $\mathrm{N}=33$, considered as $\mathrm{PS}-\mathrm{BC}$ patients) paclitaxel treatment history, and we surprisingly found that gp96 mRNA levels were apparently increased in the cancer tissues collected from BC patients with paclitaxel-resistant properties in contrast with the PS-BC patients (Fold changes: 1.92, Figure 1B). In addition, the plasma exosomes were isolated and purified from the above BC patients' blood samples, the morphology of the exosomes was photographed by performing the TEM assay (Figure S1A), and further Western Blot analysis verified that the exosome markers, including CD63 and TSG101, were expressed, but the cellular indicator $\beta$-actin was absent in the isolated exosomes (Figure
S1B), implying that the quality of the exosomes were guaranteed. Data in Figures 1C, D showed that gp96 protein was upregulated in the exosomes isolated from $\mathrm{PR}-\mathrm{BC}$ patients comparing to the PS-BC patients (Fold changes: 4.83 ). For the cellular experiments, the parental PS-BC cells (MDA-MB-453 and MCF7) were subjected to continuous low-dose paclitaxel exposure to induce the descent PR-BC cells (MDA-MB-453/ PTX and MCF7/PTX) as previously reported, and the experimental procedures were shown in Figure 1E. The MTT assay results indicated that $\mathrm{PR}-\mathrm{BC}$ cells were much more resistant to paclitaxel treatment, in contrast with the PS-BC cells (Figures 1F-I). Of note, comparing to the PS-BC cells, we found that low-dose paclitaxel increased gp96 expression levels in PR-BC cells at both mRNA and protein levels, as it indicated by Real-Time qPCR (Figure 1J) and Western Blot analysis (Figures 1K, L) results. Consistently, the exosomes were isolated from BC cells' supernatants (Figures S1A, B), and our data supported that gp96 protein tended to be enriched in the PR-BC-exo but not in the PS-BC-exo (Fold changes: 2.83,

Figures 1M, N). The above data suggested that intracellular and extracellular gp96 was closely associated with BC malignancy and drug-resistance.

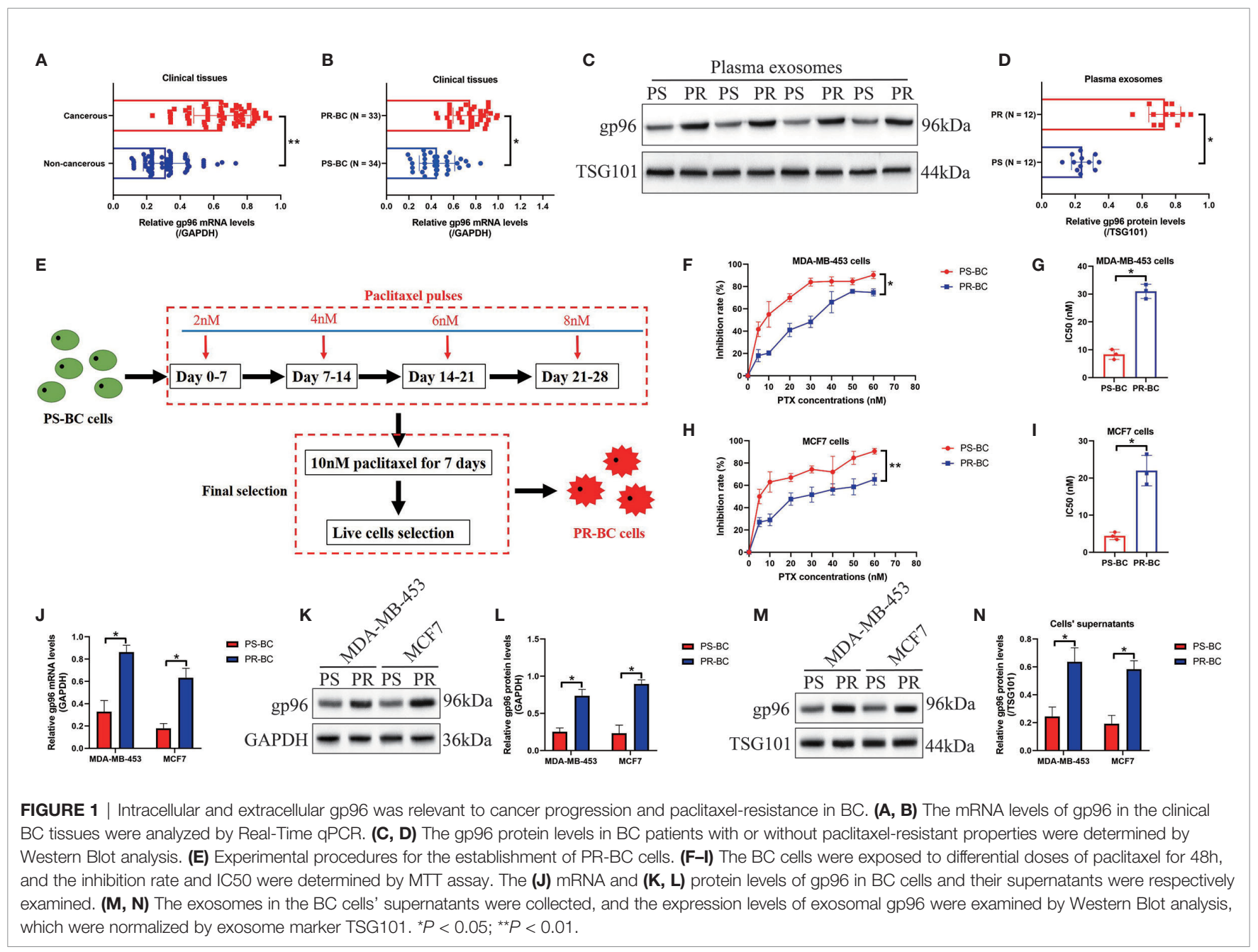




\section{HSP gp96 Regulated}

\section{Paclitaxel-Resistance in BC Cells in a p53-Dependent Manner}

The following experiments were conducted to determine the role of gp96 in regulating paclitaxel-resistance in BC cells, and to achieve this, we transfected the gp96 overexpression vectors into PS-BC cells (Figure S2A), and the gp96 downregulation vectors were delivered into the PR-BC cells (Figure S2B), respectively. The vector transfection efficiency was determined by Real-Time qPCR analysis (Figures S2A, B). Data in Figures 2A-C showed that upregulation of gp96 rescued cell viability and decreased the ratio of Annexin V-FITC or PI-positive apoptotic cells in the PSBC cells subjecting to high-dose paclitaxel stimulation, as determined by MTT assay (Figures 2A, B) and FCM assay (Figure 2C and Figures S3A, B), implying that gp96 overexpression increased paclitaxel-resistance in PS-BC cells. Conversely, we evidenced that knockdown of gp96 suppressed cell viability (Figures 2D, E) and promoted cell apoptosis (Figure 2F, Figures S3C, D) in paclitaxel-treated PR-BC cells, hinting that silence of gp96 increased paclitaxel-sensitivity in PRBC cells. The potential underlying mechanisms were also preliminarily uncovered, and previous literatures report that p53 is the hub gene for regulating paclitaxel chemo-resistance $(45,46)$, and p53 can be targeted and degraded by gp96 (47), which encouraged us to assume that gp96 might regulate $\mathrm{BC}$ cell death through modulating p53. To investigate the effects of gp96 on p53, we conducted Real-Time qPCR and Western Blot analysis, and our results hinted that gp96 merely suppressed p53 at protein levels (Fold changes: 0.63, Figures 2H, I) but not in the mRNA levels (Fold changes: 1.03, Figure 2G) in PS-BC cells. Thus, p53 was overexpressed in PS-BC cells (Figures S2CE), and the functional experiments evidenced that upregulated p53 enhanced the inhibiting effects of paclitaxel on cell viability in the PS-BC cells (Figure 2J, K). Also, p53 overexpression
A

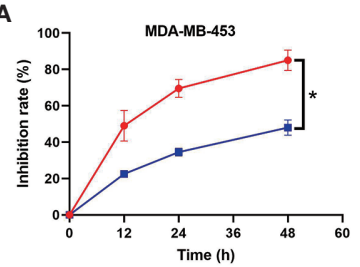

D

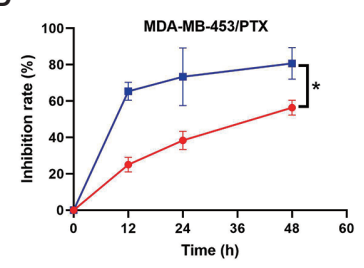

G

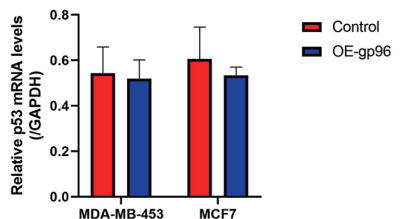

$\mathbf{J}$

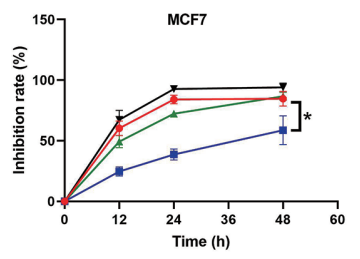

B
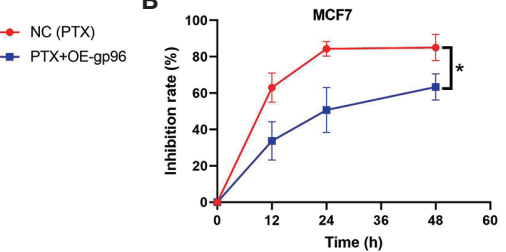

E
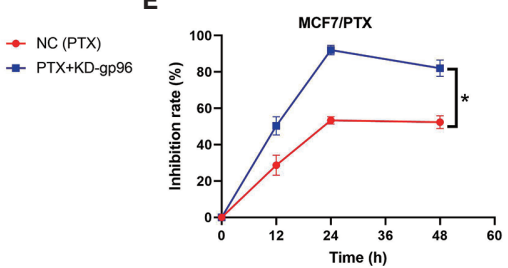

H

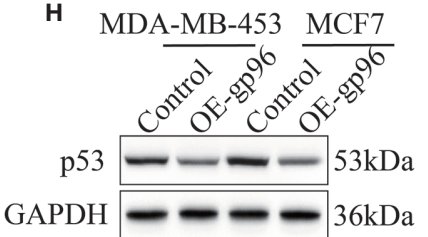

K

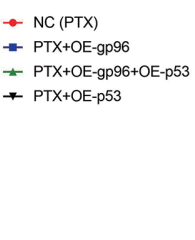

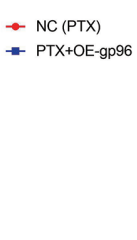

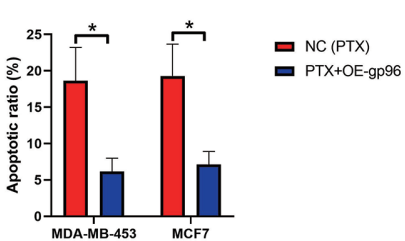

$\mathbf{F}$

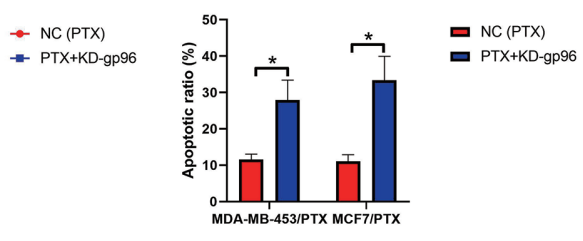

I
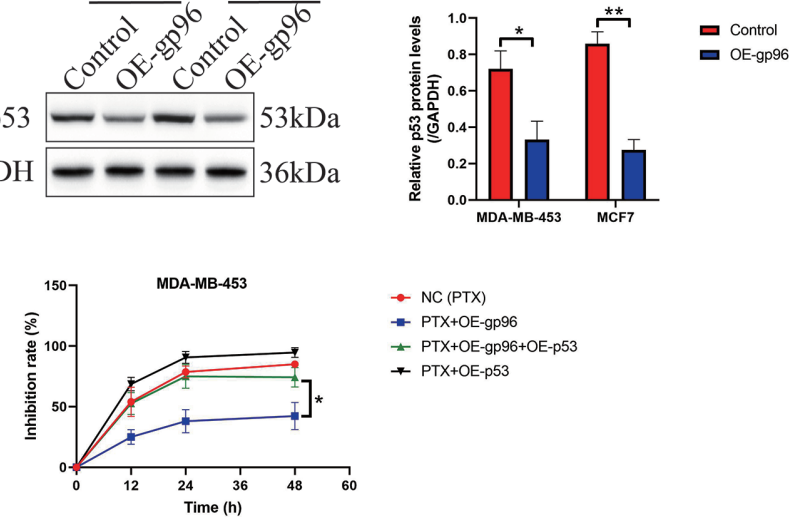

FIGURE 2 | Paclitaxel-resistance was enhanced by gp96 in BC cells through degrading p53. (A, B) Upregulation of gp96 increased paclitaxel-resistance in PS-BC cells, as determined by MTT assay. (C) Overexpressed gp96 restrained paclitaxel-induced cell apoptosis in PS-BC cells (related with Figures S3A, B). (D, E) MTT assay results evidenced that silencing gp96 increased paclitaxel-sensitivity in PR-BC cells. (F) FCM results supported that knockdown of gp96 enhanced the promoting effects of paclitaxel on cell apoptosis in PR-BC cells (related with Figures S3C, D). The (G) mRNA and (H, I) protein levels of p53 in PS-BC cells were respectively examined by Real-Time qPCR and Western Blot analysis. (J, K) The inhibition rate of paclitaxel treatment on PS-BC cells were examined by MTT assay. Note: OE-gp69 indicated gp96 overexpression. ${ }^{\star} P<0.05,{ }^{\star \star} P<0.01$. 
abrogated the regulating effects of gp96 overexpression on paclitaxel-resistance in PS-BC cells (Figures 2J, K), suggesting that intracellular gp96 controlled paclitaxel-resistance in BC cells in a p53-dependent manner.

\section{PR-BC Cells Derived Exosomes Delivered gp96 to Increase Paclitaxel-Resistance in PS-BC Cells}

Cancer cells derived exosomes contribute to chemo-resistance in multiple cancers, including $\mathrm{BC}(6,7)$, and we next investigated whether PR-BC-exo affected paclitaxel-resistance in PS-BC cells. To explore this issue, the exosomes secreted by PR-BC cells with or without gp96-deficiency were incubated with PS-BC cells, and our data showed that PKH67-labelled exosomes translocated into the PS-BC cells (Figure 3A). The following Western Blot analysis evidenced that gp96 protein was successfully delivered into the PS-BC cells by PR-BC-exo (Fold changes: 3.62 and 4.32, Figures 3B, C), and as expected, Real-Time qPCR analysis evidenced that PR-BC-exo did not affect gp96 mRNA levels in the PS-BC cells (Figure 3D). Interestingly, our MTT assay data showed that PR-BC-exo with gp96 expressions was capable of increasing cell viability in paclitaxel-treated PS-BC cells (Figures 3E, F). Consistent with this, the FCM assay results supported that paclitaxel-induced apoptotic cell death in PS-BC cells were also reversed by co-incubating cells with PR-BC-exo (Figure 3G and Figures S4A, B). However, the PR-BC-exo with gp96-deficiency did not influence paclitaxel-resistance in PS-BC cells (Figures 3E-G and Figures S4A, B), suggesting that PR-BCexo transmitted gp96 to increase paclitaxel-resistance in PS-BC cells. The in vivo experiments supported that PR-BC-exo also reversed the suppressing effects of paclitaxel on the tumorigenesis of MCF7 cells in tumor-bearing mice models (Figures 3H, I and Figures S4C, D). Those data suggested that PR-BC cells increased paclitaxel-resistance of its surrounding PS-BC cells via delivering gp96-containing exosomes.

\section{PR-BC Cells Secreted Exosomal gp96 to Activate NLRP3-Mediated Pyroptotic Cell Death in pBMSCs-Derived CD8 ${ }^{+}$T Cells}

As previously reported, gp96 participates in the regulation of immune evasion and surveillance during cancer progression (9), and $\mathrm{CD}^{+} \mathrm{T}$ is considered as the main immune cells to eliminate malignant cells by recognizing tumor-associated antigens in tumor cells $(35,36)$. However, malignant cancer cells were able to shed or hide their antigens, and a subgroup of cancer cells communicate with $\mathrm{CD}^{+} \mathrm{T}$ cells by secreting information

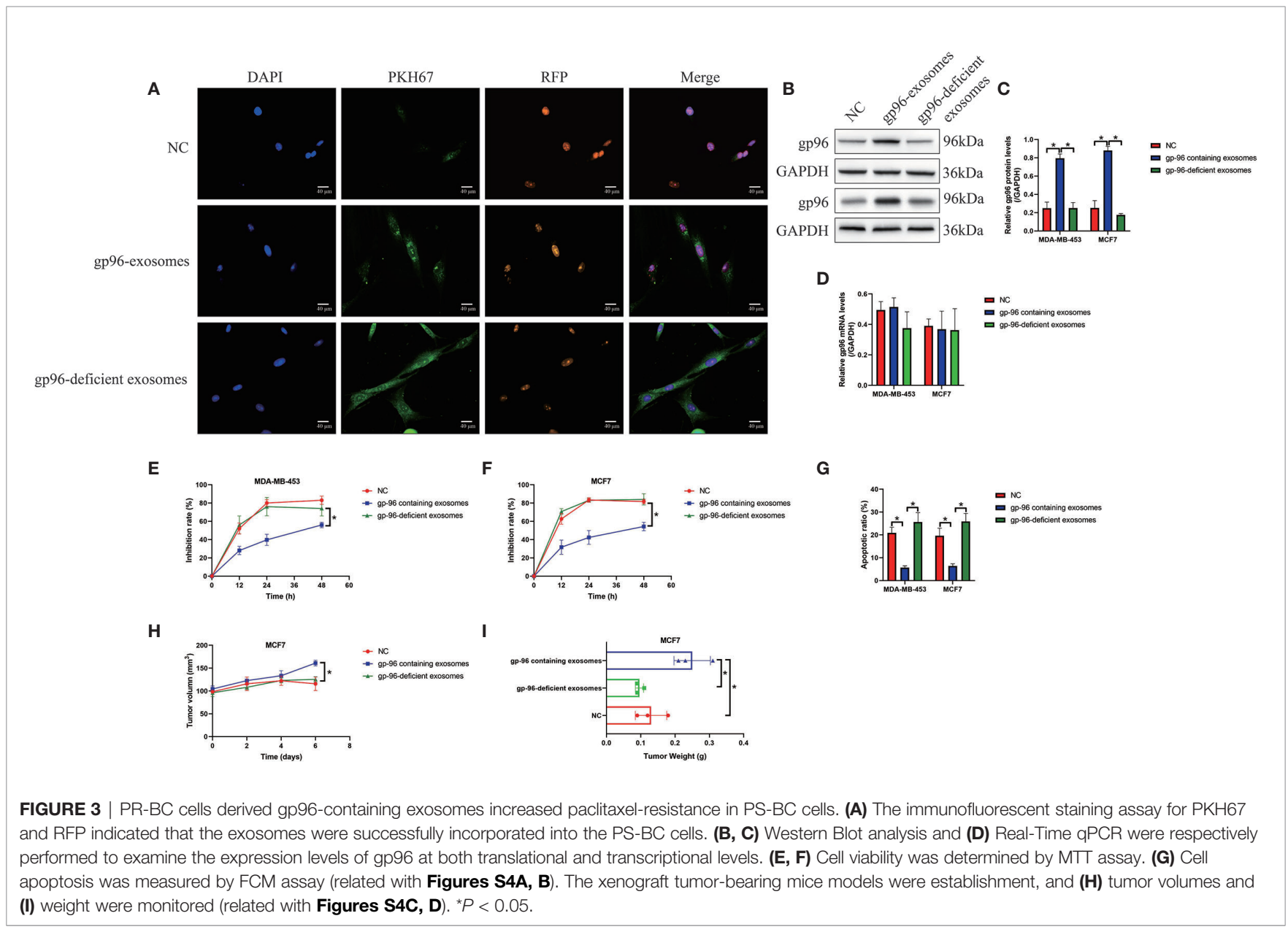


molecules, resulting in the death of those immune cells and facilitate immune evasion $(35,36)$. Thus, we considered exosomal gp96 as the communicating molecule which might mediate $\mathrm{CD}^{+}{ }^{+} \mathrm{T}$ cell death. Hence, the pBMSCs-derived CD8 ${ }^{+}$ $\mathrm{T}$ cells were isolated and were co-cultured with PR-BC-exo with or without gp96 deficiency. The EdU assay (Figures 4A, B) and MTT assay (Figure 4C) were performed, and the results showed that PR-BC-exo with gp96 expression significantly suppressed cell viability and proliferation in the CD8+ $\mathrm{T}$ cells, while PR-BC-exo with gp96 deficiency had little effects on the above cellular functions (Figures $\mathbf{4 A - C}$ ). In addition, we noticed that PR-BC-exo induced upregulation of cellular cytokines, including IL-1 $\beta$ and IL-18, in both $\mathrm{CD}^{+} \mathrm{T}$ cells (Fold changes: 3.45 and 4.32, Figure 5A) and its supernatants (Fold changes: 5.22 and 4.71, Figure 5B), as determined by Real-Time qPCR and ELISA. Since IL- $1 \beta$ and IL- 18 are classical biomarkers for pyroptotic cell death, and gp 96 has been proved to activate NLRP3 inflammasome in murine APCs (48), we then performed the following experiments to investigate whether exosomal gp96 triggered pyroptotic cell death in $\mathrm{CD}^{+} \mathrm{T}$ cells. As shown in Figure 5C, the immunofluorescent staining assay results suggested that $\mathrm{PR}-\mathrm{BC}$-exo promoted Gasdermin D expressions in $\mathrm{CD}^{+} \mathrm{T}$ cells through delivering gp96. The above results suggested that PR-BC-exo delivered gp96 to restrain cell viability in $\mathrm{CD}^{+} \mathrm{T}$ cells, which was associated with cell pyroptosis.

\section{Hypoxia Promoted Paclitaxel-Resistance and EMT in PS-BC Cells}

Hypoxia is common phenomena in solid tumors when tumor volume reaches about $2 \mathrm{~mm}$, and hypoxic pressure brings significant changes to the cellular functions of both tumor and stromal cells in the tumor microenvironment, which further facilitates angiogenesis and cancer metastasis (13-15). Of note, recent data indicate that hypoxia increases gp96 expressions through upregulating HIF-1 (9), which were verified in our study. Specifically, the PS-BC cells were subjected to HIF-1 knockdown vectors (Figure S6) and hypoxic treatments, and the cancer cells and their exosomes in the supernatants were collected. By performing Real-Time qPCR (Figure 6A) and Western Blot analysis (Figures 6B, C), we verified that hypoxia promoted gp96 generation (Fold changes: 3.22 and 4.01) and secretion (Fold changes: 2.34 and 2.91) in the PS-BC cells and supernatants, which were reversed by silencing HIF-1, suggesting that hypoxia promoted intracellular and extracellular gp96 expressions through inducing HIF-1 expressions. Then, we explored the paclitaxel-resistant characteristics of the PS-BC cells under normal or hypoxic environment (Figures 6D-H and Figures S5A, B). To achieve this, the mentioned PS-BC cells were subjected to high-dose paclitaxel treatment, and the MTT assay supported that paclitaxel especially suppressed cell viability in PS-BC cells without hypoxic stimulation (Figures 6D, E). Also, the FCM results evidenced that hypoxic PS-BC cells were much more resistant to paclitaxel-induced cell apoptosis than the normal PS-BC cells (Figures 6F, G and Figures S5A, B), suggesting that hypoxia increased paclitaxel-resistant properties in PS-BC cells. Moreover, we profiled the EMT associated makers in the PS-BC cells, and the Real-Time qPCR analysis results validated that the mRNA levels of the mesenchymal biomarkers, including ZEB1, vimentin, twist, slug, snail and fibronectin, were all elevated by hypoxic stimulations in PS-BC cells (Figures 6I, J). Taken together those data, we concluded that Hypoxia affected gp96 expressions and secretion in BC cells via inducing HIF-1, and hypoxic condition was capable of increasing paclitaxel-resistance and promoting EMT process in the PS-BC cells.

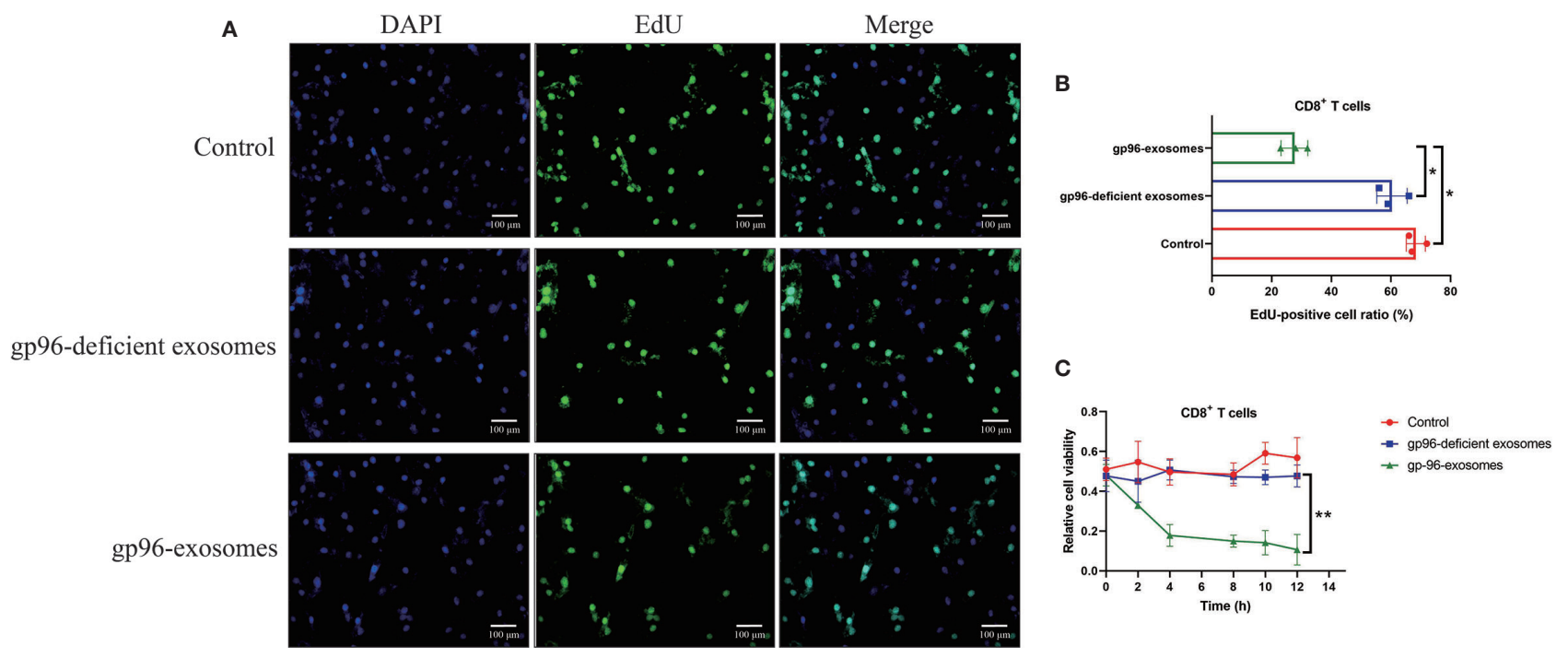

FIGURE 4 | PR-BC cells derived gp96 exosomes suppressed cell viability in the CD8 ${ }^{+} \mathrm{T}$ cells. (A, B) The EdU assay was performed to examine cell proliferation abilities in the $\mathrm{CD}^{+} \mathrm{T}$ cells. (C) Cell viability of the $\mathrm{CD}^{+} \mathrm{T}$ cells was determined by MTT assay. ${ }^{\star} P<0.05$; ${ }^{\star \star} P<0.01$. 


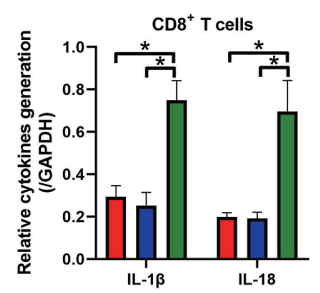

B

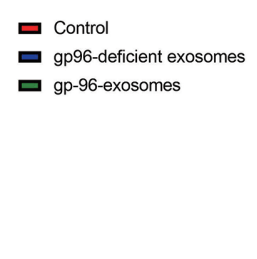

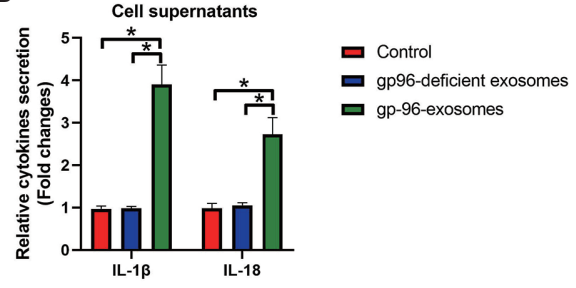

C

DAPI
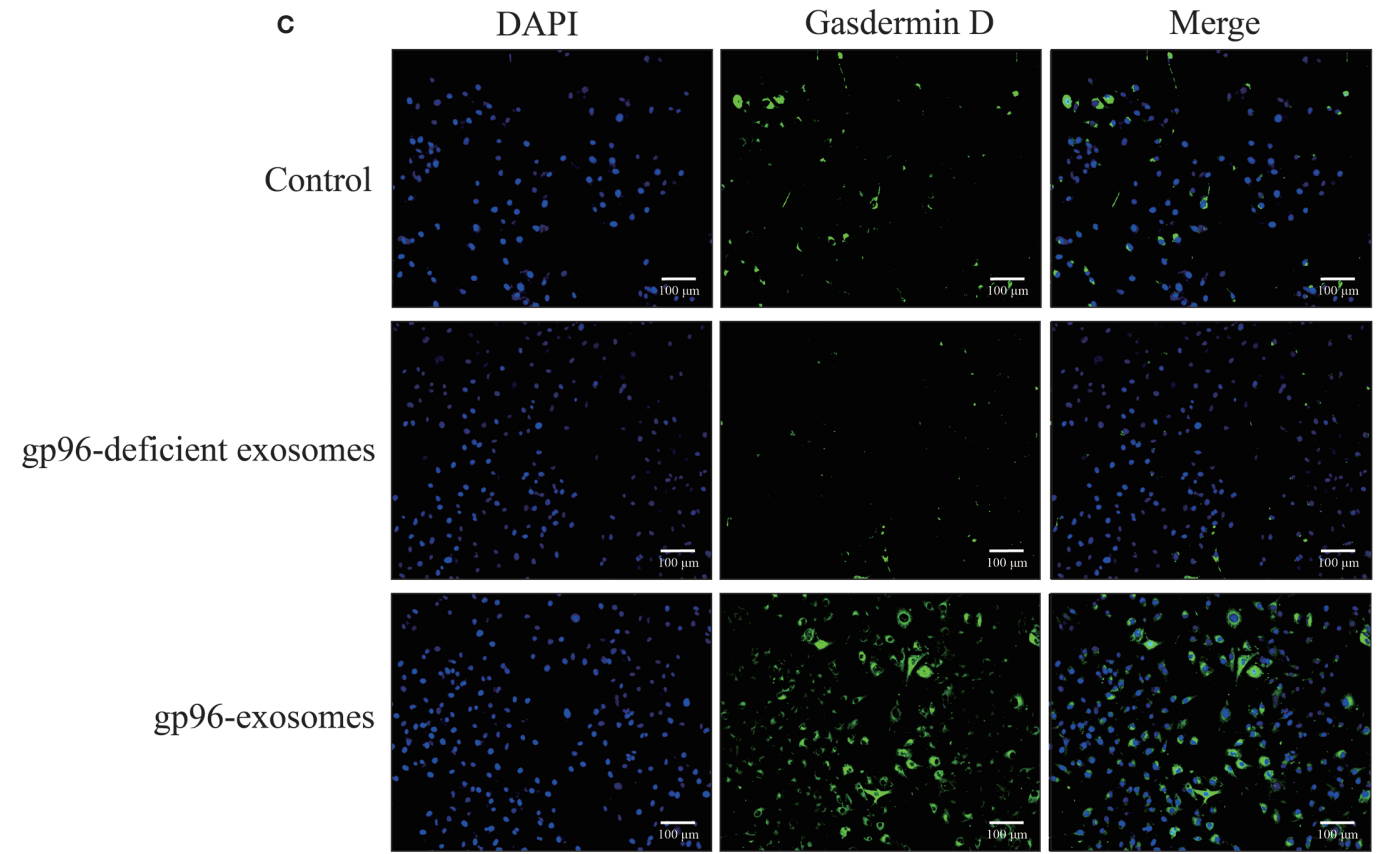

FIGURE 5 | The exosomal gp96 triggered cell pyroptosis in CD8 ${ }^{+}$T cells. (A) Real-Time qPCR was performed to determine the generation of IL-1 $\beta$ and IL-18 in the $\mathrm{CD}^{+} \mathrm{T}$ cells. (B) The secretion of IL-1 $\beta$ and IL-18 in the CD8 ${ }^{+} \mathrm{T}$ cells' supernatants were measured by ELISA. (C) The expression levels and cellular localization of Gasdermin $\mathrm{D}$ in the $\mathrm{CD}^{+} \mathrm{T}$ cells were determined by using the immunofluorescence staining assay. ${ }^{\star} P<0.05$.

\section{DISCUSSION}

Intracellular and extracellular gp96 is closely associated with cancer aggressiveness $(10,11)$ and drug resistance $(12)$, but the molecular mechanisms by which gp96 controls cancer progression and paclitaxel-resistance in $\mathrm{BC}$ have not been investigated. According to the previous publications, gp96 serves as an oncogene to facilitate BC progression $(10,11)$ and enhance paclitaxel-resistance in ovarian cancer (12), which are supported by our results that gp96 was upregulated in the paclitaxel-resistant $\mathrm{BC}(\mathrm{PR}-\mathrm{BC})$ tissues and cells, in contrast with their paclitaxel-sensitive BC (PS-BC) counterparts. To validate the biological functions of gp96, we conducted the following functional experiments and evidenced that overexpression of gp96 increased paclitaxel-resistance in PS-BC cells, whereas gp96 ablation sensitized PR-BC cells to paclitaxel treatments, suggesting that gp96 promoted paclitaxel-resistance in BC, which were supported by the previous publications (1012). Moreover, we verified that gp96 regulated paclitaxel- resistance in $\mathrm{BC}$ cells through modulating p53. As previously described, gp96 decreased p53 stability to promote its degradation in liver cancer (47), and inhibition of gp96 by its inhibitor upregulated p53 expressions to suppress Hepatitis B (HBV) replication (49). In addition, depletion of p53 increases paclitaxel-resistance in BC $(46,50,51)$, indicating that existence of p53 sustains paclitaxel-sensitivity in BC. Based on the above information, we further evidenced that gp96 degraded p53 proteins instead of its mRNA in $\mathrm{BC}$, and the promoting effects of gp96 overexpression on paclitaxel-resistance were abrogated by upregulating $\mathrm{p} 53$, which were in consistent with the previous publications $(46,50,51)$.

In addition to the intracellular gp96, recent studies suggest that gp96 is incorporated into the exosomes to act as informative molecules for cell-to-cell communication, which is pivotal for sustaining chemoresistance in multiple cancers $(8,9)$. In our experiments, we isolated the $\mathrm{BC}$ cells derived exosomes, and found that gp96 was significantly enriched in the PR-BC cell derived exosomes, instead of the PS-BC cells derived exosomes. 


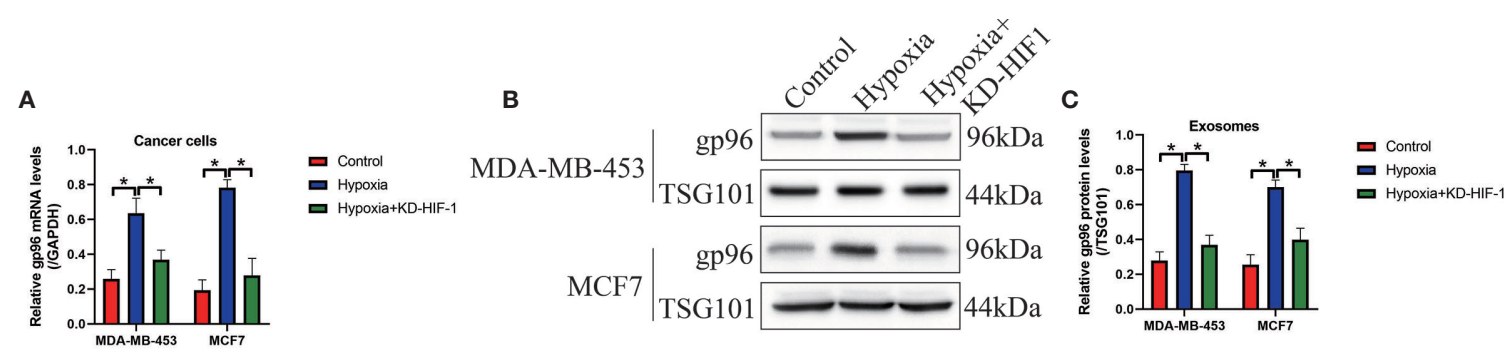

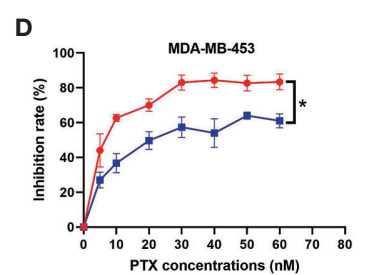

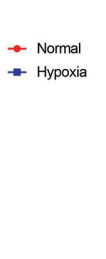

H

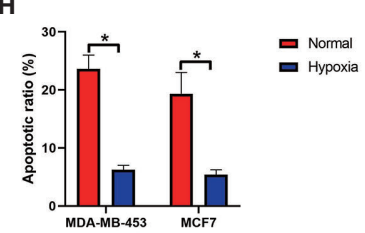

E

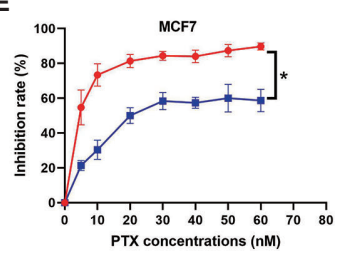

I

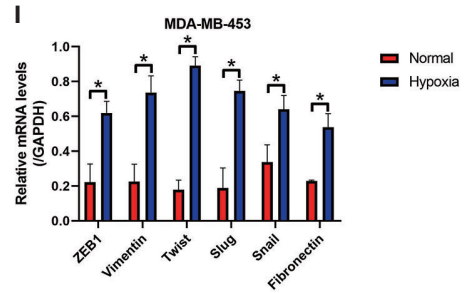

F - Normal
- Hypoxia

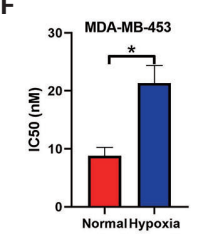

G

J

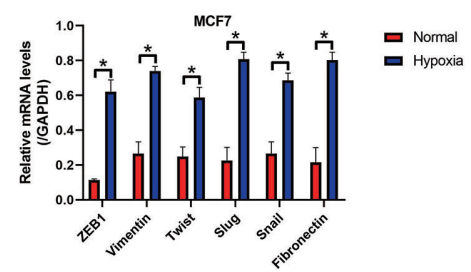

FIGURE 6 | Hypoxic conditions promoted exosomal gp96 generation and increased paclitaxel-resistance in the PS-BC cells. (A) Hypoxia increased the mRNA levels of gp96 in PS-BC cells, as determined by Real-Time qPCR analysis. (B, C) Western Blot analysis was employed to detect gp96 protein levels in the PS-BC cells' exosomes. (D, E) The cytotoxic effects of paclitaxel treatment on cell viability in the normal and hypoxic PS-BC cells were examined by MTT assay. (F, G) The IC50 values of paclitaxel in PS-BC cells were shown. (H) Hypoxia was capable of reversing paclitaxel-induced cell apoptosis in PS-BC cells (related with Figures S5A, B). (I, J) Hypoxic conditions promoted the expressions of the EMT associated markers in the PS-BC cells. Note: KD-HIF-1 suggested "knockdown of HIF-1". ${ }^{\star} P<0.05$.

Furthermore, through conducting in vitro and in vivo experiments, we found that gp96-containing exosomes increased paclitaxel-resistance in PS-BC cells, hinting that PRBC cells delivered exosomal gp96 to increase paclitaxelresistance in PS-BC cells. In addition, previous literatures report that cancer cells derived exosomes interact with immune cells to promote immune evasion during cancer pathogenesis (37-39), and researchers notice that gp96 is considered as biomarker for immune surveillance via influencing $\mathrm{CD}^{+}$and $\mathrm{CD}^{+}{ }^{+}$T-lymphocytes $(9,40)$, which are supported by our results that gp96-containing exosomes suppressed cell viability in the $\mathrm{CD}^{+} \mathrm{T}$ cells, which is the main immune cells that recognize tumor antigens $(35,36)$. Also, we verified that extracellular gp96 triggered pyroptotic cell death in $\mathrm{CD}^{+} \mathrm{T}$ cells, which is indirectly validated by the available information that gp96 activated NLRP3 inflammasome in the antigen presenting cells (APCs) (48).

Hypoxia is common phenomena in solid tumors, and deprivation of oxygen and nutrients under this situation make a small subgroup of cancer cells in the inner tumors more aggressiveness (16-18) and even resistant to chemical drugs (19, 52-55). For example, Liu et al. evidence that hypoxia facilitates chemoresistance in glioma (19), Xu et al. report that hypoxia induces chemoresistance in non-small cell lung cancer (NSCLC) (55), and Zhu et al. find that cisplatin-resistance in esophageal cancer cells was also enhanced by hypoxic conditions (54). Of note, hypoxia also promotes paclitaxel-resistance in multiple cancers (52, 53), which are supported by our results that hypoxia promoted paclitaxel-resistance in PS-BC cells. In addition, hypoxia is related with cancer metastasis (16-18), and we evidenced that hypoxia accelerated EMT process in PS-BC cells. Moreover, as previously reported, hypoxia influences cell-to-cell communications in tumor microenvironment via promoting exosomes secretion (56), and hypoxia induces gp96 upregulation (26). Based on this, we reported that hypoxia promoted exosomal gp96 generation in PS-BC cells through upregulating HIF-1, which are evidenced by the available information that HIF-1 is capable of elevating gp96 $(9,31)$.

\section{CONCLUSIONS}

Thus, we summarized the findings of this study as follows: (1) Both continuous long-term paclitaxel exposure and hypoxic conditions induced gp96 upregulation and secretion. (2) The intracellular gp96 degraded p53 and resulted in paclitaxelresistance in PS-BC cells. (3) The extracellular gp96-containing exosomes transformed the PS-BC cells into PR-BC cells. (4) PRBC cells derived gp96-containing exosomes initiated pyroptotic cell death in $\mathrm{CD}^{+} \mathrm{T}$ cells to facilitate immune evasion. 


\section{DATA AVAILABILITY STATEMENT}

The original contributions presented in the study are included in the article/Supplementary Material. Further inquiries can be directed to the corresponding author.

\section{ETHICS STATEMENT}

The studies involving human participants were reviewed and approved by Ethics Committee Affiliated to Harbin Medical University Cancer Hospital. The patients/participants provided their written informed consent to participate in this study. The animal study was reviewed and approved by Ethics Committee Affiliated to Harbin Medical University Cancer Hospital.

\section{AUTHOR CONTRIBUTIONS}

TT and JGH were co-first authors, and they contributed equally to this work. They were responsible for the conception, investigations, experiments, software, data collection/analysis, and they also drafted the initial version of the manuscript. $\mathrm{JH}$ and SL contributed to this work in terms of data analysis and visualization, they also revised the manuscript regarding to the grammatical problems. HP was the corresponding author of this study, and was responsible for the conception, guidance, funding acquisition, manuscript proofreading and submission. All authors contributed to the article and approved the submitted version.

\section{FUNDING}

This study was financially supported by the fundings as follows:

\section{REFERENCES}

1. Liu G, Zhang Z, Song Q, Guo Y, Bao P, Shui H. Circ_0006528 Contributes to Paclitaxel Resistance of Breast Cancer Cells by Regulating miR-1299/CDK8 Axis. Onco Targets Ther (2020) 13:9497-511. doi: 10.2147/OTT.S252886

2. Yang W, Gong P, Yang Y, Yang C, Yang B, Ren L. Circ-ABCB10 Contributes to Paclitaxel Resistance in Breast Cancer Through Let-7a-5p/DUSP7 Axis. Cancer Manag Res (2020) 12:2327-37. doi: 10.2147/CMAR.S238513

3. Diéras V, Han HS, Kaufman B, Wildiers H, Friedlander M, Ayoub JP, et al. Veliparib With Carboplatin and Paclitaxel in BRCA-Mutated Advanced Breast Cancer (BROCADE3): A Randomised, Double-Blind, PlaceboControlled, Phase 3 Trial. Lancet Oncol (2020) 21(10):1269-82. doi: 10.1016/S1470-2045(20)30447-2

4. Schmid P, Rugo HS, Adams S, Schneeweiss A, Barrios CH, Iwata $\mathrm{H}$, et al. Atezolizumab Plus Nab-Paclitaxel as First-Line Treatment for Unresectable, Locally Advanced or Metastatic Triple-Negative Breast Cancer (IMpassion130): Updated Efficacy Results From a Randomised, DoubleBlind, Placebo-Controlled, Phase 3 Trial. Lancet Oncol (2020) 21(1):44-59. doi: 10.1016/S1470-2045(19)30689-8

5. Tolaney SM, Guo H, Pernas S, Barry WT, Dillon DA, Ritterhouse L, et al. SevenYear Follow-Up Analysis of Adjuvant Paclitaxel and Trastuzumab Trial for Node-Negative, Human Epidermal Growth Factor Receptor 2-Positive Breast Cancer. J Clin Oncol (2019) 37(22):1868-75. doi: 10.1200/JCO.19.00066
(1) Natural Science and Technology Fund of Heilongjiang Province of China (Grant Number LH2020H126).

(2) Hai Yan Fund from Harbin Medical University Cancer Hospital (Grant Number JJZD2020-06).

(3) National Cancer Center climbing Foundation (Grant Number NCC201808B014).

(4) Wu Jieping Medical Foundation (Grant Number 320.6750.18215).

(5) Heilongjiang Postdoctoral Fund (Grant Number LBH- Q18096).

\section{SUPPLEMENTARY MATERIAL}

The Supplementary Material for this article can be found online at: https://www.frontiersin.org/articles/10.3389/fonc.2021.784777/ full\#supplementary-material

Supplementary Figure 1 | Isolation, purification and identification of the exosomes. (A) TEM was conducted to determine the morphologies of the isolated exosomes. (B) Western Blot analysis was used to examine the expression levels of the exosome-associated biomarkers.

Supplementary Figure 2 | The vector transfection efficiency of (A) gp96 overexpression in PS-BC cells, (B) gp96 downregulation in PR-BC cells, and (C-E) p53 ablation in PS-BC cells, were measured by performing Real-Time qPCR and Western Blot analysis. ${ }^{\star \star} P<0.01 ;{ }^{\star \star \star} P<0.001$.

Supplementary Figure 3 | FCM was used to examine cell apoptosis ratio in the (A, B) PS-BC cells and (C, D) PR-BC cells, respectively. ${ }^{*} P<0.05$.

Supplementary Figure 4 | (A, B) FCM was performed to determine cell apoptosis in PS-BC cells. (C, D) Tumor volumes of the xenograft tumor-bearing mice models were photographed and measured. ${ }^{*} P<0.05$.

Supplementary Figure $\mathbf{5}$ | Cell apoptosis ratio in the PS-BC cells were determined by FCM analysis. ${ }^{\star} P<0.05$.

Supplementary Figure 6 | The transfection efficiency of HIF-1 knockdown vectors was determined by performing Real-Time qPCR analysis. ${ }^{\star} P<0.05$

6. Pederson PJ, Liang H, Filonov D, Mooberry SL. Eribulin and Paclitaxel Differentially Alter Extracellular Vesicles and Their Cargo From TripleNegative Breast Cancer Cells. Cancers (Basel) (2021) 13(11):2783. doi: $10.3390 /$ cancers 13112783

7. Yang Q, Zhao S, Shi Z, Cao L, Liu J, Pan T, et al. Chemotherapy-Elicited Exosomal miR-378a-3p and miR-378d Promote Breast Cancer Stemness and Chemoresistance via the Activation of EZH2/STAT3 Signaling. J Exp Clin Cancer Res (2021) 40(1):120. doi: 10.1186/s13046-021-01901-1

8. Cianciaruso C, Phelps EA, Pasquier M, Hamelin R, Demurtas D, Alibashe Ahmed M, et al. Primary Human and Rat $\beta$-Cells Release the Intracellular Autoantigens GAD65, IA-2, and Proinsulin in Exosomes Together With Cytokine-Induced Enhancers of Immunity. Diabetes (2017) 66(2):460-73. doi: $10.2337 / \mathrm{db} 16-0671$

9. Taha EA, Ono K, Eguchi T. Roles of Extracellular HSPs as Biomarkers in Immune Surveillance and Immune Evasion. Int J Mol Sci (2019) 20(18):4588. doi: 10.3390/ijms20184588

10. Li X, Sun L, Hou J, Gui M, Ying J, Zhao H, et al. Cell Membrane Gp96 Facilitates HER2 Dimerization and Serves as a Novel Target in Breast Cancer. Int J Cancer (2015) 137(3):512-24. doi: 10.1002/ijc.29405

11. Li X, Wang B, Liu W, Gui M, Peng Z, Meng S. Blockage of Conformational Changes of Heat Shock Protein Gp96 on Cell Membrane by a $\alpha$-Helix Peptide Inhibits HER2 Dimerization and Signaling in Breast Cancer. PloS One (2015) 10(4):e0124647. doi: 10.1371/journal.pone.0124647 
12. Di Michele M, Marcone S, Cicchillitti L, Della Corte A, Ferlini C, Scambia G, et al. Glycoproteomics of Paclitaxel Resistance in Human Epithelial Ovarian Cancer Cell Lines: Towards the Identification of Putative Biomarkers. J Proteomics (2010) 73(5):879-98. doi: 10.1016/j.jprot.2009.11.012

13. Chen XJ, Deng YR, Wang ZC, Wei WF, Zhou CF, Zhang YM, et al. HypoxiaInduced ZEB1 Promotes Cervical Cancer Progression via CCL8-Dependent Tumour-Associated Macrophage Recruitment. Cell Death Dis (2019) 10 (7):508. doi: 10.1038/s41419-019-1748-1

14. Qureshi-Baig K, Kuhn D, Viry E, Pozdeev VI, Schmitz M, Rodriguez F, et al. Hypoxia-Induced Autophagy Drives Colorectal Cancer Initiation and Progression by Activating the PRKC/PKC-EZR (Ezrin) Pathway. Autophagy (2020) 16(8):1436-52. doi: 10.1080/15548627.2019.1687213

15. Vaupel P, Schmidberger H, Mayer A. The Warburg Effect: Essential Part of Metabolic Reprogramming and Central Contributor to Cancer Progression. Int J Radiat Biol (2019) 95(7):912-9. doi: 10.1080/09553002.2019.1589653

16. Niu Y, Bao L, Chen Y, Wang C, Luo M, Zhang B, et al. HIF2-Induced Long Noncoding RNA RAB11B-AS1 Promotes Hypoxia-Mediated Angiogenesis and Breast Cancer Metastasis. Cancer Res (2020) 80(5):964-75. doi: 10.1158/ 0008-5472.CAN-19-1532

17. Schito L. Hypoxia-Dependent Angiogenesis and Lymphangiogenesis in Cancer. Adv Exp Med Biol (2019) 1136:71-85. doi: 10.1007/978-3-030-12734-3_5

18. Semenza GL. Cancer-Stromal Cell Interactions Mediated by HypoxiaInducible Factors Promote Angiogenesis, Lymphangiogenesis, and Metastasis. Oncogene (2013) 32(35):4057-63. doi: 10.1038/onc.2012.578

19. Liu J, Gao L, Zhan N, Xu P, Yang J, Yuan F, et al. Hypoxia Induced Ferritin Light Chain (FTL) Promoted Epithelia Mesenchymal Transition and Chemoresistance of Glioma. J Exp Clin Cancer Res (2020) 39(1):137. doi: 10.1186/s13046-020-01641-8

20. Ling S, Shan Q, Zhan Q, Ye Q, Liu P, Xu S, et al. USP22 Promotes HypoxiaInduced Hepatocellular Carcinoma Stemness by a HIF1 $\alpha /$ USP22 Positive Feedback Loop Upon TP53 Inactivation. Gut (2020) 69(7):1322-34. doi: 10.1136/gutjnl-2019-319616

21. Wu H, Chu Y, Sun S, Li G, Xu S, Zhang X, et al. Hypoxia-Mediated Complement 1q Binding Protein Regulates Metastasis and Chemoresistance in Triple-Negative Breast Cancer and Modulates the PKC-NF- $\kappa b-V C A M-1$ Signaling Pathway. Front Cell Dev Biol (2021) 9:607142. doi: 10.3389/ fcell.2021.607142

22. Tang K, Zhu L, Chen J, Wang D, Zeng L, Chen C, et al. Hypoxia Promotes Breast Cancer Cell Growth by Activating a Glycogen Metabolic Program. Cancer Res (2021) 81(19):4949-63. doi: 10.1158/0008-5472.CAN-21-0753

23. Maciel L, de Oliveira DF, Monnerat G, Campos de Carvalho AC, Nascimento JHM. Exogenous $10 \mathrm{kDa}-H e a t$ Shock Protein Preserves Mitochondrial Function After Hypoxia/Reoxygenation. Front Pharmacol (2020) 11:545. doi: 10.3389/fphar.2020.00545

24. Madaeva IM, Kurashova NA, Semenova NV, Ukhinov EB, Kolesnikov SI, Kolesnikova LI. Heat Shock Protein HSP70 in Oxidative Stress in Apnea Patients. Bull Exp Biol Med (2020) 169(5):695-7. doi: 10.1007/s10517-02004957-9

25. Zhang G, Cheng W, Du L, Xu C, Li J. Synergy of Hypoxia Relief and Heat Shock Protein Inhibition for Phototherapy Enhancement. I Nanobiotech (2021) 19(1):9. doi: 10.1186/s12951-020-00749-5

26. Kutomi G, Tamura Y, Okuya K, Yamamoto T, Hirohashi Y, Kamiguchi K, et al. Targeting to Static Endosome Is Required for Efficient CrossPresentation of Endoplasmic Reticulum-Resident Oxygen-Regulated Protein 150-Peptide Complexes. J Immunol (2009) 183(9):5861-9. doi: 10.4049/ jimmunol.0803768

27. Chen L, Bao L, Niu Y, Wang JE, Kumar A, Xing C, et al. LncIHAT Is Induced by Hypoxia-Inducible Factor 1 and Promotes Breast Cancer Progression. Mol Cancer Res (2021) 19(4):678-87. doi: 10.1158/1541-7786.MCR-20-0383

28. Xiang L, Semenza GL. Hypoxia-Inducible Factors Promote Breast Cancer Stem Cell Specification and Maintenance in Response to Hypoxia or Cytotoxic Chemotherapy. Adv Cancer Res (2019) 141:175-212. doi: 10.1016/ bs.acr.2018.11.001

29. Zhang HS, Zhang ZG, Du GY, Sun HL, Liu HY, Zhou Z, et al. Nrf2 Promotes Breast Cancer Cell Migration via Up-Regulation of G6PD/HIF-1 $\alpha /$ Notch1 Axis. J Cell Mol Med (2019) 23(5):3451-63. doi: 10.1111/jcmm.14241

30. Yen TY, Stephen ZR, Lin G, Mu Q, Jeon M, Untoro S, et al. CatalaseFunctionalized Iron Oxide Nanoparticles Reverse Hypoxia-Induced
Chemotherapeutic Resistance. Adv Healthc Mater (2019) 8(20):e1900826. doi: 10.1002/adhm.201900826

31. Singhal S, Wiewrodt R, Malden LD, Amin KM, Matzie K, Friedberg J, et al. Gene Expression Profiling of Malignant Mesothelioma. Clin Cancer Res (2003) 9(8):3080-97.

32. Lei X, Lei Y, Li JK, Du WX, Li RG, Yang J, et al. Immune Cells Within the Tumor Microenvironment: Biological Functions and Roles in Cancer Immunotherapy. Cancer Lett (2020) 470:126-33. doi: 10.1016/j.canlet.2019.11.009

33. Liu H, Kuang X, Zhang Y, Ye Y, Li J, Liang L, et al. ADORA1 Inhibition Promotes Tumor Immune Evasion by Regulating the ATF3-PD-L1 Axis. Cancer Cell (2020) 37(3):324-39.e8. doi: 10.1016/j.ccell.2020.02.006

34. Yamamoto K, Venida A, Yano J, Biancur DE, Kakiuchi M, Gupta S, et al. Autophagy Promotes Immune Evasion of Pancreatic Cancer by Degrading MHC-I. Nature (2020) 581(7806):100-5. doi: 10.1038/s41586-020-2229-5

35. Hong W, Xue M, Jiang J, Zhang Y, Gao X. Circular RNA Circ-CPA4/ Let-7 miRNA/PD-L1 Axis Regulates Cell Growth, Stemness, Drug Resistance and Immune Evasion in Non-Small Cell Lung Cancer (NSCLC). J Exp Clin Cancer Res (2020) 39(1):149. doi: 10.1186/s13046-020-01648-1

36. Liu Z, Zhou Q, Wang Z, Zhang $H$, Zeng $H$, Huang Q, et al. Intratumoral TIGIT(+) CD8(+) T-Cell Infiltration Determines Poor Prognosis and Immune Evasion in Patients With Muscle-Invasive Bladder Cancer. J Immunother Cancer (2020) 8(2):e000978. doi: 10.1136/jitc-2020-000978

37. Chen G, Huang AC, Zhang W, Zhang G, Wu M, Xu W, et al. Exosomal PD-L1 Contributes to Immunosuppression and is Associated With Anti-PD-1 Response. Nature (2018) 560(7718):382-6. doi: 10.1038/s41586-018-0392-8

38. Kulkarni B, Kirave P, Gondaliya P, Jash K, Jain A, Tekade RK, et al. Exosomal miRNA in Chemoresistance, Immune Evasion, Metastasis and Progression of Cancer. Drug Discovery Today (2019) 24(10):2058-67. doi: 10.1016/ j.drudis.2019.06.010

39. Qadir F, Aziz MA, Sari CP, Ma H, Dai H, Wang X, et al. Transcriptome Reprogramming by Cancer Exosomes: Identification of Novel Molecular Targets in Matrix and Immune Modulation. Mol Cancer (2018) 17(1):97. doi: 10.1186/s12943-018-0846-5

40. Radolovic P, Grebic D, Mustac E, Sebaher I, Mamic J, Miletic WM. Heat Shock Protein Gp96 and CD4+ and CD8+ T-Lymphocytes Expression as Prognostic Factors in Various Molecular Types of Invasive Breast Carcinoma. Neoplasma (2020) 67(2):421-9. doi: 10.4149/neo_2020_190601N478

41. You L, Wu W, Wang X, Fang L, Adam V, Nepovimova E, et al. The Role of Hypoxia-Inducible Factor 1 in Tumor Immune Evasion. Med Res Rev (2021) 41(3):1622-43. doi: 10.1002/med.21771

42. Han J, Han B, Wu X, Hao J, Dong X, Shen Q, et al. Knockdown of lncRNA H19 Restores Chemo-Sensitivity in Paclitaxel-Resistant Triple-Negative Breast Cancer Through Triggering Apoptosis and Regulating Akt Signaling Pathway. Toxicol Appl Pharmacol (2018) 359:55-61. doi: 10.1016/j.taap.2018.09.018

43. Zhang X, Sai B, Wang F, Wang L, Wang Y, Zheng L, et al. Hypoxic BMSCDerived Exosomal miRNAs Promote Metastasis of Lung Cancer Cells via STAT3-Induced EMT. Mol Cancer (2019) 18(1):40. doi: 10.1186/s12943-0190959-5

44. Wang X, He Q, Shen H, Xia A, Tian W, Yu W, et al. TOX Promotes the Exhaustion of Antitumor CD8(+) T Cells by Preventing PD1 Degradation in Hepatocellular Carcinoma. J Hepatol (2019) 71(4):731-41. doi: 10.1016/ j.jhep.2019.05.015

45. Parmakhtiar B, Burger RA, Kim JH, Fruehauf JP. HIF Inactivation of P53 in Ovarian Cancer Can Be Reversed by Topotecan, Restoring Cisplatin and Paclitaxel Sensitivity. Mol Cancer Res (2019) 17(8):1675-86. doi: 10.1158/ 1541-7786.MCR-18-1109

46. Xue J, Chi Y, Chen Y, Huang S, Ye X, Niu J, et al. MiRNA-621 Sensitizes Breast Cancer to Chemotherapy by Suppressing FBXO11 and Enhancing P53 Activity. Oncogene (2016) 35(4):448-58. doi: 10.1038/onc.2015.96

47. Wu B, Chu X, Feng C, Hou J, Fan H, Liu N, et al. Heat Shock Protein Gp96 Decreases P53 Stability by Regulating Mdm2 E3 Ligase Activity in Liver Cancer. Cancer Lett (2015) 359(2):325-34. doi: 10.1016/j.canlet.2015.01.034

48. Wang Y, Sedlacek AL, Pawaria S, Xu H, Scott MJ, Binder RJ. Cutting Edge: The Heat Shock Protein Gp96 Activates Inflammasome-Signaling Platforms in APCs. J Immunol (2018) 201(8):2209-14. doi: 10.4049/jimmunol.1800505

49. Qian L, Fan H, Ju Y, Chen L, Li X, Ye X, et al. A Peptide-Based Inhibitor of Gp96 Suppresses HBsAg Expression and HBV Replication by Upregulation of P53. J Gen Virol (2019) 100(8):1241-52. doi: 10.1099/jgv.0.001289 
50. Aborehab NM, Elnagar MR, Waly NE. Gallic Acid Potentiates the Apoptotic Effect of Paclitaxel and Carboplatin via Overexpression of Bax and P53 on the MCF-7 Human Breast Cancer Cell Line. J Biochem Mol Toxicol (2021) 35(2): e22638. doi: 10.1002/jbt.22638

51. Khordadmehr M, Shahbazi R, Baradaran B, Sadreddini S, Shanebandi D, Hajiasgharzadeh K. Restoring of miR-193a-5p Sensitizes Breast Cancer Cells to Paclitaxel Through P53 Pathway. Adv Pharm Bull (2020) 10(4):595-601. doi: 10.34172/apb.2020.071

52. Feng L, Shen F, Zhou J, Li Y, Jiang R, Chen Y. Hypoxia-Induced UpRegulation of miR-27a Promotes Paclitaxel Resistance in Ovarian Cancer. Biosci Rep (2020) 40(4):BSR20192457. doi: 10.1042/BSR20192457

53. Li K, Li M, Luo Z, Mao Y, Yu Y, He Y, et al. Overcoming the Hypoxia-Induced Drug Resistance in Liver Tumor by the Concurrent Use of Apigenin and Paclitaxel. Biochem Biophys Res Commun (2020) 526(2):321-7. doi: 10.1016/ j.bbrc.2020.03.010

54. Zhu ZJ, Pang Y, Jin G, Zhang HY, Wang WH, Liu JW, et al. Hypoxia Induces Chemoresistance of Esophageal Cancer Cells to Cisplatin Through Regulating the IncRNA-EMS/miR-758-3p/WTAP Axis. Aging (Albany NY) (2021) 13 (13):17155-76. doi: 10.18632/aging.203062

55. Xu R, Luo X, Ye X, Li H, Liu H, Du Q, et al. SIRT1/PGC-1 $\alpha /$ PPAR- $\gamma$ Correlate With Hypoxia-Induced Chemoresistance in Non-Small Cell Lung Cancer. Front Oncol (2021) 11:682762. doi: 10.3389/fonc.2021.682762
56. Yang H, Zhang H, Yang Y, Wang X, Deng T, Liu R, et al. Hypoxia Induced Exosomal circRNA Promotes Metastasis of Colorectal Cancer via Targeting GEF-H1/RhoA Axis. Theranostics (2020) 10(18):8211-26. doi: 10.7150/ thno.44419

Conflict of Interest: The authors declare that the research was conducted in the absence of any commercial or financial relationships that could be construed as a potential conflict of interest.

Publisher's Note: All claims expressed in this article are solely those of the authors and do not necessarily represent those of their affiliated organizations, or those of the publisher, the editors and the reviewers. Any product that may be evaluated in this article, or claim that may be made by its manufacturer, is not guaranteed or endorsed by the publisher.

Copyright $\odot 2021$ Tian, Han, Huang, Li and Pang. This is an open-access article distributed under the terms of the Creative Commons Attribution License (CC BY). The use, distribution or reproduction in other forums is permitted, provided the original author(s) and the copyright owner(s) are credited and that the original publication in this journal is cited, in accordance with accepted academic practice. No use, distribution or reproduction is permitted which does not comply with these terms. 